\title{
Statistical Methods for the Investigation of Solvolysis Mechanisms Illustrated by the Chlorides of the Carbomethoxy Protecting Groups NVOC and FMOC
}

\author{
Malcolm J. D’Souza, ${ }^{1}$ Jasbir K. Deol, ${ }^{1}$ Maryeah T. Pavey, ${ }^{1}$ and Dennis N. Kevill ${ }^{2}$ \\ ${ }^{1}$ Department of Chemistry, Wesley College, 120 N. State Street, Dover, DE 19901-3875, USA \\ ${ }^{2}$ Department of Chemistry and Biochemistry, Northern Illinois University, DeKalb, IL 60115-2862, USA \\ Correspondence should be addressed to Malcolm J. D’Souza; dsouzama@wesley.edu
}

Received 20 October 2014; Revised 20 November 2014; Accepted 24 November 2014

Academic Editor: Radosław Kowalski

Copyright (C) 2015 Malcolm J. D'Souza et al. This is an open access article distributed under the Creative Commons Attribution License, which permits unrestricted use, distribution, and reproduction in any medium, provided the original work is properly cited.

\begin{abstract}
The solvolysis of 4,5-dimethoxy-2-nitrobenzyl chloroformate (NVOC-Cl, 1 ) is followed at $25.0^{\circ} \mathrm{C}$ in twenty hydroxylic solvents. A comparison with previously published rates for benzyl chloroformate and $p$-nitrobenzyl chloroformate indicates that the inductive effect of the nitro and the two methoxy groups strongly influences the rate of reaction. For $\mathbf{1}$, the specific rates of solvolysis are correlated using an extended Grunwald-Winstein (G-W) treatment. A direct comparison with the data for phenyl chloroformate $(\mathrm{PhOCOCl})$ in identical solvents strongly suggests that the addition step within an addition-elimination mechanism is ratedetermining for both substrates. A reevaluation of the kinetic data for 9-fluorenylmethyl chloroformate (FMOC-Cl, 2) involves a correlation of $\log \left(k / k_{o}\right)_{2}$ versus $\log \left(k / k_{o}\right)_{\text {PhocoCl. }}$. In this plot, deviations were observed in solvents rich in a hydrogen-bonding fluoroalcohol component. Omitting the aqueous fluoroalcohol rate measurements for 2 in an analysis using the extended G-W equation suggested the occurrence of dual pathways differing in the dependences upon the ionizing power and nucleophilicity of the solvent. In addition, the fluorenyl ring is rotated out of the plane containing the ether oxygen and, as a result, $\mathrm{PhOCOCl}$ is found to solvolyze 20 times faster than 2 in ethanol and methanol.
\end{abstract}

\section{Introduction}

6-Nitroveratryl chloroformate is the synonym for 4,5-dimethoxy-2-nitrobenzyl chloroformate (NVOC-Cl, 1). Due to its chemical stability and ease of removal, this chloroformate ester is used to introduce the 6-nitroveratryl group (NVOC protecting group) in a variety of amino acid synthetic applications [1]. Similarly, 9-fluorenylmethyl chloroformate (FMOC-Cl, 2) is used to introduce the fluorenylmethyloxycarbonyl (FMOC) group to give the FMOC carbamate in solid and solution phase peptide synthetic processes [1]. In addition, both groups are incorporated in different methods used for synthesizing diverse polymer sequences for agricultural products [2]. The molecular structures for NVOC-Cl (1) and FMOC-Cl (2) and their corresponding 3D images $\left(\mathbf{1}^{\prime}\right)$ and $\left(2^{\prime}\right)$ are shown in Figure 1. Details of the commercial 3D image rendering program are provided in Section 4.
Chloroformates (ROCOCl) in general are important organic building blocks [1-3] employed in the chemical industry due to reduced reactivity when compared to the rapidly reacting acid chlorides of the RCOCl type. The slower rates of reaction are a result of the alkoxycarbonyl (or aryloxycarbonyl) resonance stabilization [3]. Several groups [4-13] have extensively examined the mechanism of solvolysis of phenyl chloroformate $(\mathrm{PhOCOCl}, 3)$ in a very wide range of solvents. For PhOCOCl, in 49 solvents, a twostep addition-elimination (association-dissociation) process (Scheme 1) was believed $[6,11]$ to prevail.

The Grunwald-Winstein (G-W) equations ((1) and (2)) $[14,15]$ are linear free energy relationships (LFERs) used to quantify influences of solvent effects on a given substrate. In (1) and (2), $k$ is the specific rates of solvolysis in a given solvent, $k_{o}$ is the specific rate in $80 \%$ aqueous ethanol (an arbitrarily fixed standard solvent), and $c$ is a constant 


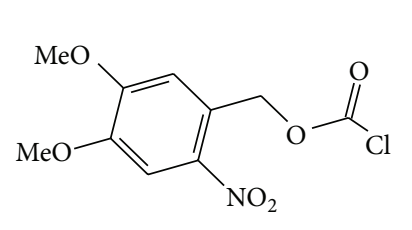

(1)

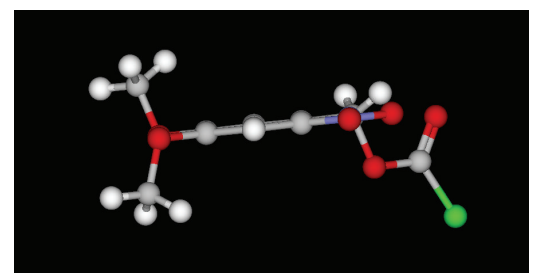

$\left(1^{\prime}\right)$

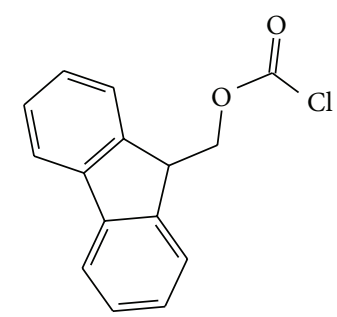

(2)

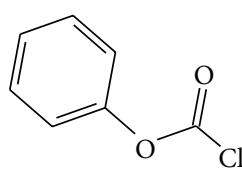

(3)

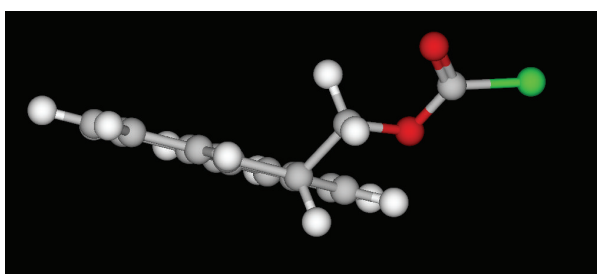

$\left(\mathbf{2}^{\prime}\right)$

FIGURE 1: Molecular structures of 4,5-dimethoxy-2-nitrobenzyl chloroformate (NVOC-Cl, 1), 9-fluorenylmethyl chloroformate (FMOC-Cl, 2), and phenyl chloroformate (PhOCOCl, 3). The 3D structures for 4,5-dimethoxy-2-nitrobenzyl chloroformate $\left(\mathbf{1}^{\prime}\right)$ and 9-fluorenylmethyl chloroformate $\left(\mathbf{2}^{\prime}\right)$.<smiles>[R]OC(=O)Cl</smiles><smiles>[R]OC(=O)[Se-]</smiles>

Scheme 1: Stepwise addition-elimination mechanism through a tetrahedral intermediate for chloroformate esters.

residual term. In both equations [14, 15], $m$ is a measure of the sensitivity to changes in solvent ionizing power $Y$. In (2) [15], $l$ is a measure of the sensitivity to changes in solvent nucleophilicity $N$. Scales for both $N[16,17]$ and $Y$ $[18,19]$ are established. An $N_{\mathrm{T}}$ [17] scale based on the solvolysis of S-methyldibenzothiophenium ion and a $Y_{\mathrm{Cl}}[18-20]$ scale based on the solvolysis of 1-adamantyl chloride are the preferred scales for the Grunwald-Winstein type analyses of chloroformate esters:

$$
\begin{gathered}
\log \left(\frac{k}{k_{o}}\right)=m Y+c, \\
\log \left(\frac{k}{k_{o}}\right)=l N+m Y+c .
\end{gathered}
$$

Bentley [21-25] prefers the use of the one-term G-W equation (1) to analyze rate profiles. He also suggested [21-25] the use of similarity models $\left(Y_{\text {sim }}\right)$ to interpret dispersions observed when there is $\pi$-bond resonance stabilization adjacent to the reaction site. Alternatively, we prefer [26-32] modifying (1) and (2) to evaluate and explain the solvolysis of substrates with $\pi$-electron conjugation (including $\alpha$-haloalkyl aryl compounds) at the $\alpha$-carbon or in presence of intramolecular anchimeric assistance.

Recently, two review chapters have appeared $[33,34]$ showing the use of the G-W equations within studies of the solvolyses of haloformate esters and their thioanalogs. In these chapters, when using (2), we reemphasize $[6,11,31$, $33,34]$ the use of the $l$ value of 1.66 and $m$ value of 0.56 $(l / m$ ratio of 2.96) obtained for $\mathrm{PhOCOCl}(3)$ as an appropriate standard for a bimolecular carbonyl-addition pathway (Scheme 1) with a rate-determining addition step. We have shown $[31,33-36]$ that $l / m$ values $>2.7$ are typical ratios for acyl halide solvolyses proceeding by an addition-elimination (A-E) pathway with the addition step being rate-determining.

In addition, for the solvolyses of octyl chloroformate and fluoroformate, we determined [35] the $k_{\mathrm{Cl}} / k_{\mathrm{F}}$ ratio to be somewhat below unity in mixtures of water with ethanol (EtOH), acetone, dioxane, or 2,2,2-trifluoroethanol (TFE). This is consistent with our initial proposal [6] of a rate-determining addition step in an addition-elimination process for haloformate esters. In solvents of very low nucleophilicity and very high ionizing power, an ionization mechanism was observed for some chloroformates [31, 33, 34]. We showed $[31,33,34,36]$ that the G-W $l / m$ ratios between 0.5 and 1.0 are indicative of a unimolecular ionization $\left(S_{N} 1\right)$ process with appreciable rear-side nucleophilic solvation, while values much smaller than 0.5 suggest the occurrence of an ionization-fragmentation process.

Like 1 and 2, benzyl chloroformate $\left(\mathrm{C}_{6} \mathrm{H}_{5} \mathrm{CH}_{2} \mathrm{OCOCl}\right.$, $\mathrm{CBZ}-\mathrm{Cl})$ and $p$-nitrobenzyl chloroformate ( $p$ $\mathrm{NO}_{2} \mathrm{C}_{6} \mathrm{H}_{4} \mathrm{CH}_{2} \mathrm{OCOCl}, \mathrm{PNZ}-\mathrm{Cl}$ ) are chloroformate esters that are utilized in peptide synthesis $[1,2]$. For $\mathrm{CBZ}-\mathrm{Cl}$ in solvolysis, an $l / m$ value of 0.38 was obtained in eleven fluoroalcohol-containing solvents and an $l / m$ value of 3.42 
TABLE 1: Specific rates of solvolysis $(k)$ of $\mathbf{1}$ in several binary solvents at $25.0^{\circ} \mathrm{C}$ and literature values for $N_{\mathrm{T}}$ and $Y_{\mathrm{Cl}}$.

\begin{tabular}{|c|c|c|c|}
\hline Solvent $(\%)^{\mathrm{a}}$ & 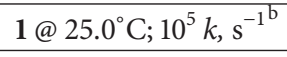 & $N_{\mathrm{T}}{ }^{\mathrm{c}}$ & $Y_{\mathrm{Cl}}^{\mathrm{d}}$ \\
\hline $100 \% \mathrm{EtOH}$ & $73.6 \pm 1.2$ & 0.37 & -2.50 \\
\hline $90 \% \mathrm{EtOH}$ & $116 \pm 5$ & 0.16 & -0.90 \\
\hline $80 \% \mathrm{EtOH}$ & $147 \pm 10$ & 0.00 & 0.00 \\
\hline $100 \% \mathrm{MeOH}$ & $125 \pm 10$ & 0.17 & -1.2 \\
\hline $90 \% \mathrm{MeOH}$ & $187 \pm 22$ & -0.01 & -0.20 \\
\hline $80 \% \mathrm{MeOH}$ & $299 \pm 14$ & -0.06 & 0.67 \\
\hline $90 \%$ acetone & $3.23 \pm 0.15$ & -0.35 & -2.39 \\
\hline $80 \%$ acetone & $11.6 \pm 0.6$ & -0.37 & -0.80 \\
\hline $70 \%$ acetone & $23.3 \pm 0.2$ & -0.42 & 0.17 \\
\hline $97 \%$ TFE $(w / w)$ & $0.056 \pm 0.003$ & -3.30 & 2.83 \\
\hline $90 \% \operatorname{TFE}(w / w)$ & $0.346 \pm 0.025$ & -2.55 & 2.85 \\
\hline $70 \% \operatorname{TFE}(\mathrm{w} / \mathrm{w})$ & $3.39 \pm 0.24$ & -1.98 & 2.96 \\
\hline $50 \% \operatorname{TFE}(\mathrm{w} / \mathrm{w})$ & $16.9 \pm 0.7$ & -1.73 & 3.16 \\
\hline $60 \mathrm{~T}-40 \mathrm{E}$ & $5.77 \pm 0.23$ & -0.94 & 0.63 \\
\hline $40 \mathrm{~T}-60 \mathrm{E}$ & $17.2 \pm 1.0$ & -0.34 & 0.48 \\
\hline $20 \mathrm{~T}-40 \mathrm{E}$ & $34.0 \pm 2.0$ & 0.08 & -1.42 \\
\hline $90 \% \operatorname{HFIP}(w / w)$ & $0.065 \pm 0.002$ & -3.84 & 4.31 \\
\hline $80 \%$ HFIP $(w / w)$ & $0.117 \pm 0.021$ & -3.31 & 3.99 \\
\hline 70\% HFIP (w/w) & $3.61 \pm 0.10$ & -2.94 & 3.83 \\
\hline $50 \% \operatorname{HFIP}(w / w)$ & $9.71 \pm 0.22$ & -2.49 & 3.80 \\
\hline
\end{tabular}

${ }^{\mathrm{a}}$ Substrate concentration of ca. $0.005 \mathrm{M}$; binary solvents on a volume-volume basis at $25.0^{\circ} \mathrm{C}$, except for TFE- $\mathrm{H}_{2} \mathrm{O}$ and $\mathrm{HFIP}-\mathrm{H}_{2} \mathrm{O}$ solvents which are on a weight-weight basis. T-E are TFE-ethanol mixtures. ${ }^{\mathrm{b}}$ With associated standard deviation. ${ }^{\mathrm{c}}$ References [16, 17]. ${ }^{\mathrm{d}}$ References [18-20].

was obtained in the remaining fifteen pure and aqueousorganic mixtures [37]. These ratios suggest a dichotomy of mechanism, with an ionization-fragmentation process accompanied by a loss of carbon dioxide occurring in the highly ionizing fluoroalcohol mixtures and an A-E process being dominant in the more nucleophilic solvents [37]. The presence of the solvolysis-decomposition (ionization-fragmentation) pathway for $\mathrm{CBZ}-\mathrm{Cl}$ in the aqueous fluoroalcohols was confirmed by product studies showing varying amounts of the benzyl chloride decomposition product being formed [37]. For PNZ-Cl, the $l / m$ ratio of 3.50 observed over the full range of solvent type was consistent with a carbonyl-addition (A-E) process $[37,38]$. The $k_{\mathrm{MeOH}} / k_{\mathrm{MeOD}}$ ratio of 2.42 found $[37,38]$ for $\mathrm{PNZ}-\mathrm{Cl}$ is a typical value for a carbonyl-addition pathway that is assisted by general-base catalysis [38].

Here we report on the specific rate constants obtained for NVOC-Cl (1) in twenty solvents of widely varying nucleophilicity $\left(N_{\mathrm{T}}\right)$ and ionizing power values $\left(Y_{\mathrm{Cl}}\right)$. We statistically analyze and report on the correlation values obtained for NVOC-Cl using the extended Grunwald-Winstein treatment (2). We compare the rate constants and the $l / m$ ratio obtained (for NVOC-Cl) to the previously published data for $\mathrm{CBZ}-\mathrm{Cl}$ [37] and $\mathrm{PNZ}-\mathrm{Cl}[37,38]$. We also consider the resonance contributions from substituent effects [39] as a result of the presence of the nitro group and the two methoxy groups in NVOC-Cl.

Koh and Kang [40] completed a comprehensive evaluation using (2) of the rate profiles obtained for FMOC-Cl (2) in 33 aqueous-organic mixtures at $45.0^{\circ} \mathrm{C}$. Omitting the
TFE-EtOH mixtures in their calculations using (2), they obtained an $l$ value of 0.95 and an $m$ value of 0.39 . They also observed a kinetic solvent isotope effect $\left(k_{\mathrm{MeOH}} / k_{\mathrm{MeOD}}\right)$ ratio of 2.20. Basing their conclusions on their $l$ and $m$ values, they proposed that the solvolysis of $\mathbf{2}$ proceeds through a bimolecular $\mathrm{S}_{\mathrm{N}} 2$ process [40].

Using (2), we reanalyze the Koh and Kang data [40] for FMOC-Cl (2) in all of the 33 solvents. Their reported $k_{\mathrm{MeOH}} / k_{\mathrm{MeOD}}$ value (2.20) [40] was close to the prior recorded KSIE ratio for PNZ-Cl $(2.42)[37,38]$ where a carbonyladdition (A-E) process was definitively proposed. To gain further insights into the reactivity of NVOC-Cl (1) and FMOCCl (2), we employed Bentley's [21-25] similarity model approach and used the previously published $\log \left(k / k_{o}\right)$ values $[6,11]$ for $\mathrm{PhOCOCl}(3)$ solvolyses as the $Y_{\text {sim }}$ scale.

\section{Results and Discussion}

In Table 1, we present the specific rates of solvolysis for 4,5-dimethoxy-2-nitrobenzyl chloroformate (NVOC-Cl, 1) in twenty binary aqueous-organic mixtures with varying $N_{\mathrm{T}}$ and $Y_{\mathrm{Cl}}$ values. The solvent mix includes the highly ionizing mixtures of aqueous fluoroalcohols where a unimolecular $\mathrm{S}_{\mathrm{N}} 1$-type (ionization) mechanism was proposed for several chloroformates [31, 33, 34].

In ethanol $(\mathrm{EtOH})$, methanol $(\mathrm{MeOH})$, and acetone, the specific rates of reaction for $\mathbf{1}$ increase with an increase in water content in the solvent mixture. The rate constants also increase with the added water component in the aqueous 
TABLE 2: Correlations of the specific rates of solvolysis of 1-3, CBZ-Cl, and PNZ-Cl using the extended Grunwald-Winstein equation (2).

\begin{tabular}{lcccccccc}
\hline Substrate & $n^{\mathrm{a}}$ & $l^{\mathrm{b}}$ & $m^{\mathrm{b}}$ & $c^{\mathrm{b}}$ & $R^{\mathrm{c}}$ & $F^{\mathrm{d}}$ & $l / m$ & Mechanism \\
\hline $\mathbf{1}$ & 20 & $1.48 \pm 0.13$ & $0.52 \pm 0.08$ & $0.04 \pm 0.11$ & 0.966 & 119 & 2.85 & $\mathrm{~A}-\mathrm{E}$ \\
$\mathbf{2}^{\mathrm{e}, \mathrm{f}}$ & 26 & $1.64 \pm 0.04$ & $0.54 \pm 0.04$ & $0.13 \pm 0.06$ & 0.954 & 116 & 3.04 & $\mathrm{~A}-\mathrm{E}$ \\
$\mathbf{3}^{\mathrm{g}}$ & 49 & $1.66 \pm 0.05$ & $0.56 \pm 0.03$ & $0.15 \pm 0.07$ & 0.980 & 568 & 2.96 & A-E \\
& 15 & $1.95 \pm 0.16$ & $0.57 \pm 0.05$ & $0.16 \pm 0.15$ & 0.966 & 83 & 3.42 & A-E \\
${\mathrm{CBZ}-\mathrm{Cl}^{\mathrm{h}}}$ & 11 & $0.25 \pm 0.05$ & $0.66 \pm 0.06$ & $-2.05 \pm 0.11$ & 0.976 & 80 & 0.38 & Ionization-fragmentation \\
PNZ$-C l^{\mathrm{i}}$ & 19 & $1.61 \pm 0.09$ & $0.46 \pm 0.04$ & $0.04 \pm 0.22$ & 0.975 & 157 & 3.50 & A-E \\
\hline
\end{tabular}

${ }^{a} n$ is the number of solvents. ${ }^{b}$ With associated standard error. ${ }^{\mathrm{c}}$ Correlation coefficient. ${ }^{\mathrm{d}} F$-test value. ${ }^{\mathrm{e}}$ Values taken from [40]. ${ }^{\mathrm{f}}$ Excluding the data points in aqueous HFIP and aqueous TFE, in regression calculations. Values taken from [40]. ${ }^{\mathrm{g}}$ Correlation data from $[11] .{ }^{\mathrm{h}}$ Correlation data from [37]. ${ }^{\mathrm{i}}$ Correlation data from $[37,38]$.

2,2,2-trifluoroethanol (TFE- $\left.\mathrm{H}_{2} \mathrm{O}\right)$ and 1,1,1,3,3,3-hexafluoro2-propanol (HFIP- $\left.\mathrm{H}_{2} \mathrm{O}\right)$. In the TFE-EtOH mixtures, there is an increase in the rates of reaction as the proportion of ethanol is increased. The patterns of specific rates observed for the twenty solvents suggest that the nucleophilic component is critical in the transition-state structure.

A comparison of the pseudo-first order rates for NVOC$\mathrm{Cl}(\mathbf{1}), \mathrm{PNZ}-\mathrm{Cl}[37,38]$, and $\mathrm{CBZ}-\mathrm{Cl}[37]$ at $25.0^{\circ} \mathrm{C}$ reveals sequences where $k_{\mathrm{NVOC}-\mathrm{Cl}}>k_{\mathrm{PNZ}-\mathrm{Cl}}>k_{\mathrm{CBZ}-\mathrm{Cl}}$ in the pure alcohols, in common binary mixtures of aqueous ethanol, methanol, and acetone and in the TFE-EtOH solvents. This rate trend indicates that the carbonyl-carbon reaction center in NVOC-Cl carries a much greater partial positive charge than the carbonyl reaction centers in PNZ-Cl and CBZ-Cl.

The 90\% TFE is the only common aqueous fluoroalcohol in which the NVOC-Cl (1), PNZ-Cl, and CBZ-Cl are studied at $25.0^{\circ} \mathrm{C}$ and the rate trend is $k_{\mathrm{CBZ}-\mathrm{Cl}}>k_{\mathrm{NVOC}-\mathrm{Cl}}>k_{\mathrm{PNZ}-\mathrm{Cl}}$. In the highly ionizing $90 \% \mathrm{HFIP}, \mathrm{CBZ}-\mathrm{Cl}$ solvolyzes at a rate that is $\mathbf{1 7 7}$ times faster than $\mathbf{1}$ and in $97 \%$ TFE, CBZ-Cl is 34 times faster than 1 . For $\mathrm{CBZ}-\mathrm{Cl}$, an ionization-fragmentation reaction was previously proposed [37] in all of the aqueous fluoroalcohols.

Figure 2 shows a plot of $\log \left(k / k_{o}\right)$ for 4,5-dimethoxy-2nitrobenzyl chloroformate (1) against $\log \left(k / k_{o}\right)$ for phenyl chloroformate (3) in the twenty common pure and binary solvents studied. The excellent correlation coefficient $(R=$ $0.993)$ and $F$-test value (1316) are strong statistical indicators that a carbonyl-addition (A-E) process is also the dominant process for 1 in all of the twenty solvents studied. The slope for this plot is $0.89 \pm 0.02$. The choice of 3 as the standard is because the mechanism of solvolyses is well established $[6,11]$. Its choice follows the rationale for choosing $p$-methoxybenzoyl chloride solvolyses as the standard [24] when unimolecular solvolyses of acyl chlorides (including chloroformate esters) are believed to be involved.

In Table 2, we report on the G-W analyses obtained for 1 using (2) in all twenty solvents. For $\mathbf{1}$, we get an $l$ value of $1.48 \pm 0.13$, an $m$ value of $0.52 \pm 0.08, c=0.04 \pm 0.11, R=$ 0.966 , and an $F$-test value of 119 . In the identical 20 solvents, a G-W analysis for 3 results in $l=1.62 \pm 0.14, m=0.55 \pm 0.09$, $c=0.22 \pm 0.13, R=0.967$, and $F$-test $=122$. In these 20 solvents, the resulting $l / m$ ratios for $\mathbf{1}(2.85)$ and $\mathbf{3}$ (2.95) show that the ratio for 3 is marginally higher. This indicates that the mechanisms for $\mathbf{1}$ and $\mathbf{3}$ are essentially indistinguishable and

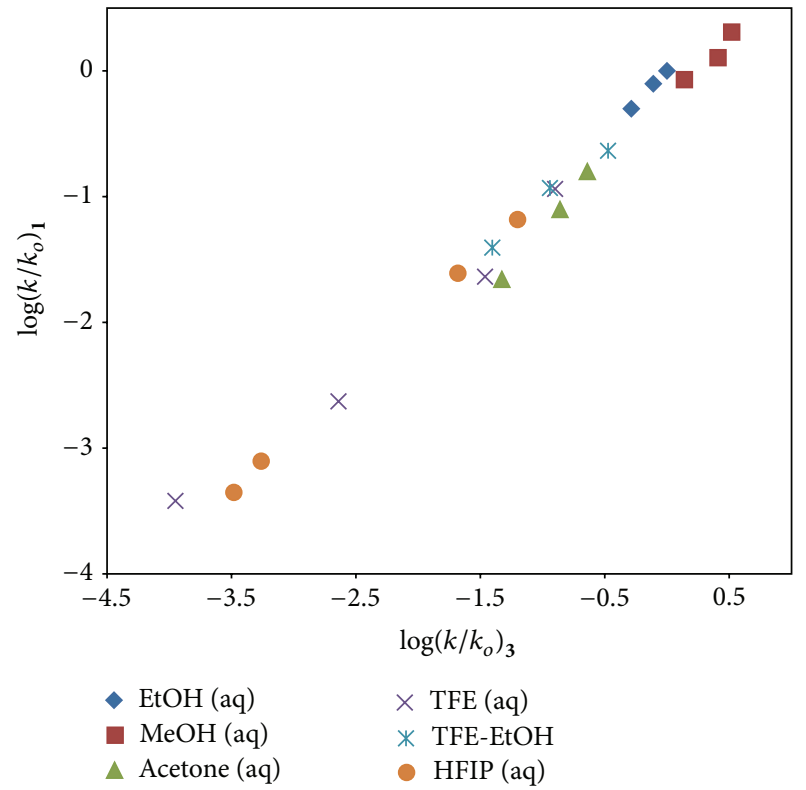

FIGURE 2: The plot of $\log \left(k / k_{o}\right)$ for 4,5-dimethoxy-2-nitrobenzyl chloroformate (1) at $25.0^{\circ} \mathrm{C}$ against $\log \left(k / k_{o}\right)$ for phenyl chloroformate (3) at $25.0^{\circ} \mathrm{C}$ in the twenty common pure and binary solvents studied.

that the tetrahedral transition states in a carbonyl-addition process are very similar.

A plot of $\log \left(k / k_{o}\right)$ for 4,5-dimethoxy-2-nitrobenzyl chloroformate (1) against $1.48 N_{\mathrm{T}}+0.52 Y_{\mathrm{Cl}}$ in the twenty pure and binary solvents studied is shown in Figure 3 . For use in this figure, we used (2), the previously published rate for $3[6,11]$ in $80 \% \mathrm{EtOH}$, and an $l$ value of 1.66 and $m$ value of $0.56[6,11]$ to calculate a specific rate of $0.276 \times 10^{-5} \mathrm{~s}^{-1}$ for solvolysis of 3 , in $80 \%$ HFIP.

In Figure 1, the 3D image for 4,5-dimethoxy-2-nitrobenzyl chloroformate $\left(\mathbf{1}^{\prime}\right)$ visibly shows that the two methoxy oxygens, the nitro group, and the aromatic ring are all very coplanar. As a result a greater inductive effect [39] is introduced in NVOC-Cl and therefore, in solvents where an addition-elimination process is proposed to be dominant, it solvolyzes much faster than PNZ-Cl and CBZ-Cl [37, 38]. 


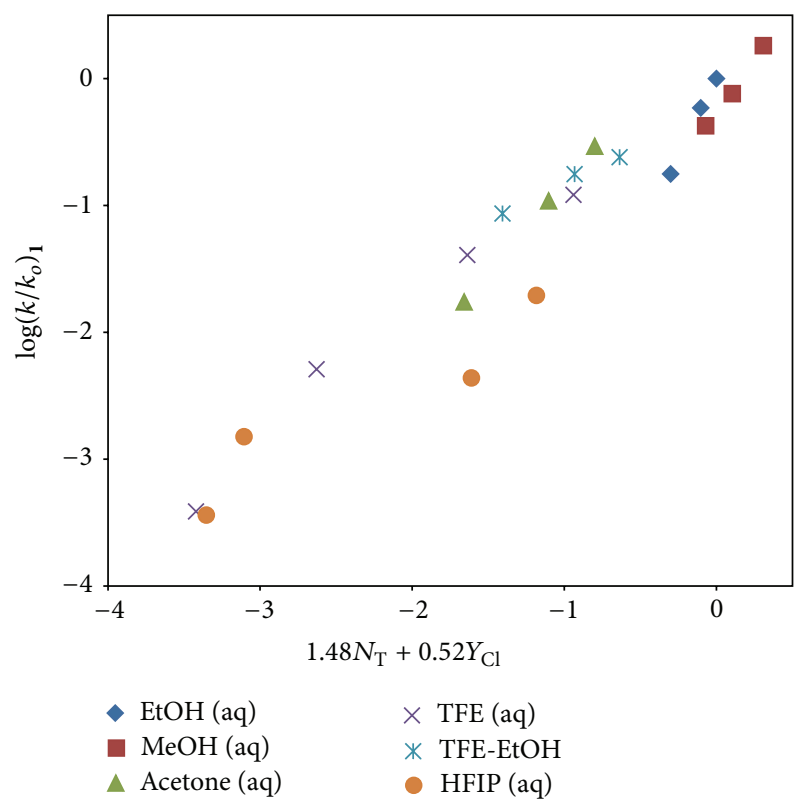

FIGURE 3: The plot of $\log \left(k / k_{o}\right)$ for 4,5-dimethoxy-2-nitrobenzyl chloroformate (1) against $1.48 N_{\mathrm{T}}+0.52 Y_{\mathrm{Cl}}$ in the twenty pure and binary solvents studied.

In 30 solvents (without the TFE-EtOH mixture data points), Koh and Kang proposed [40] a bimolecular $\mathrm{S}_{\mathrm{N}} 2$ process for FMOC-Cl (2) on the basis of the magnitudes of the $l(0.95)$ and $m(0.39)$ values obtained.

Using (2) for all 33 solvents, we acquire an $l$ value of $1.02 \pm 0.08, m=0.44 \pm 0.04, c=-0.04 \pm 0.07, R=0.925$, and an $F$-test value of 89 .

Figure 4 shows the plot of the $\log \left(k / k_{o}\right)$ values for 9 -fluorenylmethyl chloroformate (2) against the $\log \left(k / k_{o}\right)$ values for phenyl chloroformate (3) in all of the thirty-three common pure and binary solvents studied [40]. The correlation coefficient obtained for this plot is marginally acceptable with an $R$ value of $0.924, F$-test $=180$, and slope $=0.64 \pm 0.05$. The graph (Figure 4) also shows the aqueous fluoroalcohols lying above the regression line. When this happens for the TFE- $\mathrm{H}_{2} \mathrm{O}$ and HFIP- $\mathrm{H}_{2} \mathrm{O}$ mixtures, earlier reports [11, 31, 3336] on the solvolytic studies of chloroformate esters have indicated that a mechanistic shift occurs to one favoring an ionization process. Excluding the seven aqueous fluoroalcohol (TFE- $\mathrm{H}_{2} \mathrm{O}$ and HFIP- $\mathrm{H}_{2} \mathrm{O}$ ) data points, the regression analysis for the remaining 26 solvents of $\log \left(k / k_{o}\right)_{2}$ versus $\log \left(k / k_{o}\right)_{3}$ results in a significantly improved correlation coefficient, $R=0.980$, and $F$-test value $=588$, with a slope of $0.88 \pm 0.04$. This linear association is robust and firmly indicates that, in these 26 solvents, the mechanism of reaction of $\mathbf{2}$ is very similar to that observed for 3 .

An analysis using (2) for solvolyses of 2 in the 26 solvents (reported in Table 2) leads to values of $R=0.954, l=1.65 \pm$ $0.13, m=0.54 \pm 0.04, c=0.13 \pm 0.06$, and $F$-test $=116$. The $l / m$ ratio of 3.04 is very similar to $l / m$ ratios observed [11, 31, 33-36] for other acyl halide solvolyses which are believed to proceed by an addition-elimination (A-E) process with a

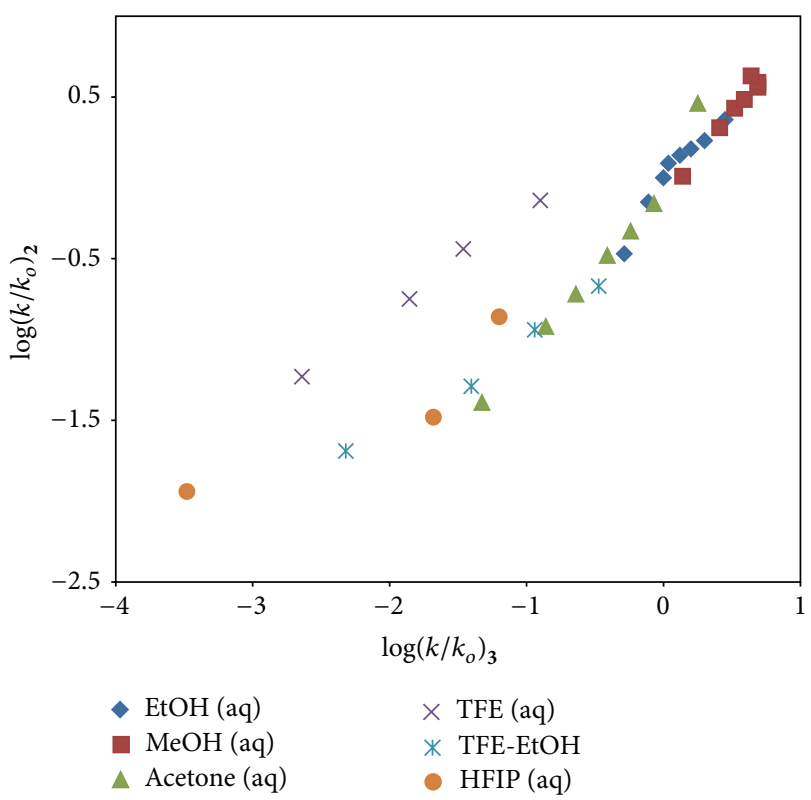

FIGURE 4: The plot of $\log \left(k / k_{o}\right)$ for 9-fluorenylmethyl chloroformate (2) against $\log \left(k / k_{o}\right)$ for phenyl chloroformate (3) in the thirty-three common pure and binary solvents studied.

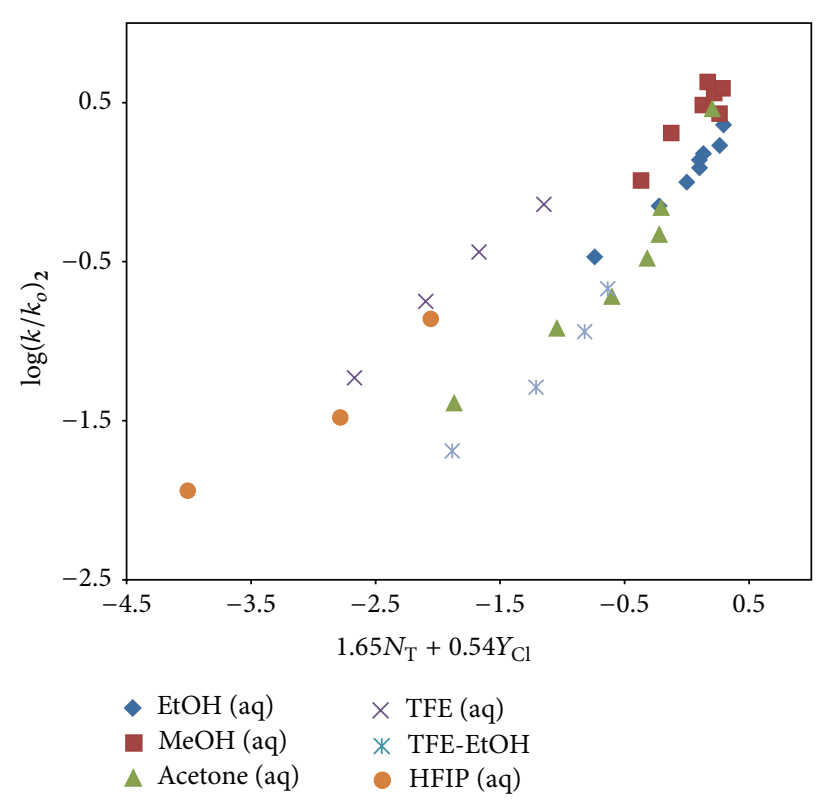

FIGURE 5: The plot of $\log \left(k / k_{o}\right)$ for 9-fluorenylmethyl chloroformate (2) against $1.65 N_{\mathrm{T}}+0.54 Y_{\mathrm{Cl}}$ in the thirty-three pure and binary solvents studied. The points for TFE- $\mathrm{H}_{2} \mathrm{O}$ and HFIP- $\mathrm{H}_{2} \mathrm{O}$ are not included in the correlation. They are added to show the extent of their deviation from the correlation.

rate-determining addition step. A plot of $\log \left(k / k_{o}\right)_{2}$ against $1.65 N_{\mathrm{T}}+0.54 Y_{\mathrm{Cl}}$ for the 26 solvents is shown in Figure 5. The points for TFE- $\mathrm{H}_{2} \mathrm{O}$ and $\mathrm{HFIP}-\mathrm{H}_{2} \mathrm{O}$ are not included in the correlation but they are added to the plot to show the extent 
of their deviation from the line of best fit. In these highly ionizing aqueous fluoroalcohols, we propose as the dominant mechanism an ionization $\left(\mathrm{S}_{\mathrm{N}} 1\right)$ process which involves rearside nucleophilic solvation.

In the identical 26 solvents, the two-term G-W (2) analysis for PhOCOCl (3) yields $R=0.949, l=1.99 \pm 0.16$, $m=0.59 \pm 0.04, c=0.28 \pm 0.07$, and $F$-test $=104$. The $l / m$ ratio $=3.37$ observed for 3 is higher than the $l / m$ ratio of 3.04 obtained above for 2 .

There are four solvents, 100\% EtOH, 80\% EtOH, 100\% $\mathrm{MeOH}$, and 50\% TFE, in which solvolyses of both $2[40]$ and $3[6,11]$ are studied at the same temperature $\left(25.0^{\circ} \mathrm{C}\right)$. A direct comparison of the specific rates of reaction for these solvents shows that $\mathrm{PhOCOCl}$ (3) is 19 times faster than FMOC-Cl (2) in 100\% EtOH, 13 times faster in $80 \% \mathrm{EtOH}, 20$ times faster in $100 \% \mathrm{MeOH}$, and 4 times faster in 50\% TFE. These ratios being slightly larger in the more nucleophilic solvents are consistent with the $l / m$ ratio (3.37) being slightly larger than that of 2 (3.04).

Additionally, the 3D image for FMOC-Cl $\left(2^{\prime}\right)$ shown in Figure 1 shows that the fluorenyl ring is forced out of the plane of the ether oxygen and that the ring is far removed from the carbonyl reaction center. As a result, any potential inductive or mesomeric effects exerted by the fluorenyl ring (through resonance) would be very weak with little influence on the rates of reaction of 2 .

\section{Conclusions}

For 4,5-dimethoxy-2-nitrobenzyl chloroformate (NVOC-Cl, 1) a very good correlation was obtained from the use of the extended Grunwald-Winstein equation. The resultant $\mathrm{l} / \mathrm{m}$ ratio of 2.85 is close to the $l / m$ ratio of 2.95 obtained for phenyl chloroformate (PhOCOCl, 3 ) in an identical set of solvents. These values suggest a similarity of transition-state structures for the two compounds and an addition-elimination (A-E) process with a rate-determining addition step is proposed for 1.

The 3D image for NVOC-Cl $\left(\mathbf{1}^{\prime}\right)$ shows that the two ether oxygens, the nitro group, and the aromatic ring are all in the same plane. Consequently relative to other benzylic substrates (PNZ-Cl and $\mathrm{CBZ}-\mathrm{Cl}$ ) a strong inductive effect is present in $\mathbf{1}$, and it solvolyzes at a much faster rate in solvents where the carbonyl-addition-elimination mechanism (A-E) is believed to be dominant $\left(k_{1}>k_{\mathrm{PNZ}-\mathrm{Cl}}>k_{\mathrm{CBZ}-\mathrm{Cl}}\right)$.

The exclusion of the rate data in the seven aqueous fluoroalcohols for solvolyses of $\mathbf{2}$ leads to much improved correlations using the two-term Grunwald-Winstein equation. The $l / m$ ratio of 3.04 and the significantly improved correlation observed in the $\log \left(k / k_{o}\right)_{2}$ versus $\log \left(k / k_{o}\right)_{3}$ regression plot are a strong indication that a two-step carbonyl-addition (AE) process is occurring in the remaining 26 solvents. An ionization $\left(\mathrm{S}_{\mathrm{N}} 1\right)$ process probably accompanied by rear-side solvation is proposed for $\mathbf{2}$ in the seven TFE- $\mathrm{H}_{2} \mathrm{O}$ and HFIP$\mathrm{H}_{2} \mathrm{O}$ mixtures.

A 3D image of 9-fluorenylmethyl chloroformate (FMOC$\mathrm{Cl}, 2^{\prime}$ ) shows that the fluorenyl ring is twisted out of the plane containing the ether oxygen. This reduces any inductive or mesomeric effect and hence in the four common solvents studied at $25.0^{\circ} \mathrm{C}$, the $\mathrm{PhOCOCl}$ substrate was found to solvolyze at a rate that was 4 to 20 times faster than 2 .

\section{Experimental Section}

The 4,5-dimethoxy-2-nitrobenzyl chloroformate (NVOC-Cl, $97 \%$, Sigma-Aldrich) was used as received. An approximately $1 \mathrm{M}$ stock solution containing NVOC-Cl (1) in acetonitrile (99.8\%, Sigma-Aldrich) was first made and a substrate concentration of at least $0.005 \mathrm{M}$ in a variety of binary solvents was used in all of the experiments. All of the organic solvents were commercially available and they were purified using methods described previously [6]. The kinetic runs in constant temperature water baths were followed after sampling, using the titrimetric method. The specific rates and associated standard deviations, as presented in Table 1, were obtained by averaging all of the values from, at least, duplicate runs.

Multiple regression analyses were carried out using the Excel 2010 package from the Microsoft Corporation [41]. The $3 \mathrm{D}$ images presented in Figure 1 were computed using the KnowItAll Informatics System [42]. The KnowItAll platform contains a 3D molecular rendering program SymApps that uses a modified MM2 force field minimization module to convert 2D structure drawings to 3D images [42].

\section{Disclosure}

Jasbir K. Deol and Maryeah T. Pavey completed this research under the direction of Malcolm J. D'Souza as undergraduate research assistants in the DE-INBRE and DE-EPSCR Sponsored Wesley College Directed Research Program in Chemistry $[43,44]$. Jasbir K. Deol presented a part of this work as a poster (CHED 270) in the CHED-Division of Analytical Chemistry at the 247th National American Chemical Society (ACS) Meeting, Dallas, TX, in March 16-20, 2014. At this national ACS conference, this poster earned a Certificate of Recognition. Recently, Jasbir K. Deol was also awarded a Cannon Scholarship on a National Science Foundation (NSF) S-STEM (NSF-DUE 135554) program. Dennis N. Kevill is a collaborator on this project.

\section{Conflict of Interests}

The authors declare that there is no conflict of interests regarding the publication of this paper.

\section{Acknowledgments}

The Wesley College Directed Research Program is supported through Federal and State awards. The authors acknowledge support from an Institutional Development Award (IDeA) from the National Institute of General Medical Sciences (NIGMS) at the National Institutes of Health (NIH Grant no. P20GM103446, Delaware INBRE program); a National Science Foundation (NSF) Experimental Program to Stimulate Competitive Research Grant EPS-0814251 (Delaware EPSCoR program); an NSF ARI-R2 Grant 0960503; an NSF 
S-STEM Grant 1355554; and the State of Delaware. The DEINBRE and DE-EPSCoR grants were obtained through the leadership of the University of Delaware and the authors sincerely appreciate their efforts.

\section{References}

[1] T. W. Greene and P. G. M. Wuts, Protective Groups in Organic Synthesis, John Wiley \& Sons, Hoboken, NJ, USA, 1991.

[2] J. E. Pemberton, R. L. Polt, R. M. Maier, and C. S. Coss, "Synthesis of glycolipids," U.S. Patent Application 14/041,251, September 2013.

[3] D. N. Kevill, "Chloroformate esters and related compounds," in Acyl Halides, S. Patai, Ed., The Chemistry of the Functional Groups, chapter 12, pp. 381-453, John Wiley \& Sons, New York, NY, USA, 1972.

[4] A. Queen, "Kinetics of the hydrolysis of acyl chlorides in pure water," Canadian Journal of Chemistry, vol. 45, no. 14, pp. 16191629, 1967.

[5] I. S. Koo, K. Yang, K. Kang, H. K. Oh, and I. Lee, "Stoichiometric solvation effects. Product-rate correlation for solvolyses of phenyl chloroformate in alcohol-water mixtures," Bulletin of the Korean Chemical Society, vol. 17, no. 6, pp. 520-524, 1996.

[6] D. N. Kevill and M. J. D'Souza, "Correlation of the rates of solvolysis of phenyl chloroformate," Journal of the Chemical Society, Perkin Transactions 2, vol. 9, no. 2, pp. 1721-1724, 1997.

[7] I. S. Koo, K. Yang, K. Kang, and I. Lee, "Transition-state variation in the solvolyses of para-substituted phenyl chloroformates in alcohol-water mixtures," Bulletin of the Korean Chemical Society, vol. 19, no. 9, pp. 968-973, 1998.

[8] I. S. Koo, J. S. Lee, K. Yang, K. Kang, and I. Lee, "The studies on substituent and kinetic solvent isotope effect in solvolyses of phenyl chloroformates," Bulletin of the Korean Chemical Society, vol. 5, pp. 573-576, 1999.

[9] M. Muñoz, A. Rodríguez, M. del Mar Graciani, and M. L. Moyá, "Micellar medium effects on the hydrolysis of phenyl chloroformate in ionic, zwitterionic, nonionic, and mixed micellar solutions," International Journal of Chemical Kinetics, vol. 34, no. 7, pp. 445-451, 2002.

[10] T. W. Bentley, H. C. Harris, Z. H. Ryu, G. T. Lim, D. D. Sung, and S. R. Szajda, "Mechanisms of solvolyses of acid chlorides and chloroformates. Chloroacetyl and phenylacetyl chloride as similarity models," Journal of Organic Chemistry, vol. 70, no. 22, pp. 8963-8970, 2005.

[11] D. N. Kevill, F. Koyoshi, and M. J. D’Souza, “Correlations of the specific rates of solvolysis of aromatic carbamoyl chlorides, chloroformates, chlorothionoformates, and chlorodithioformates revisited," International Journal of Molecular Sciences, vol. 8, no. 4, pp. 346-362, 2007.

[12] B. Denegri and O. Kronja, "Nucleofugality of phenyl and methyl carbonates," The Journal of Organic Chemistry, vol. 72, no. 22, pp. 8427-8433, 2007.

[13] T. W. Bentley, "Structural effects on the solvolytic reactivity of carboxylic and sulfonic acid chlorides. Comparisons with gas-phase data for cation formation," The Journal of Organic Chemistry, vol. 73, no. 16, pp. 6251-6257, 2008.

[14] E. Grunwald and S. Winstein, "The correlation of solvolysis rates," Journal of the American Chemical Society, vol. 70, no. 2, pp. 846-854, 1948.

[15] S. Winstein, E. Grunwald, and H. Walter Jones, "The correlation of solvolysis rates and the classification of solvolysis reactions into mechanistic categories," Journal of the American Chemical Society, vol. 73, no. 6, pp. 2700-2707, 1951.

[16] D. N. Kevill, "Development and uses of scales of solvent nucleophilicity," in Advances in Quantative Structure-Property Relationships, M. Charton, Ed., vol. 1, pp. 81-115, JAI Press, Greenwich, Conn, USA, 1996.

[17] D. N. Kevill and S. W. Anderson, "An improved scale of solvent nucleophilicity based on the solvolysis of the S-methyldibenzothiophenium ion," Journal of Organic Chemistry, vol. 56, no. 5, pp. 1845-1850, 1991.

[18] T. W. Bentley and G. E. Carter, "The $S_{N} 2-S_{N} 1$ spectrum. 4. The SN2 (intermediate) mechanism for solvolyses of tert-butyl chloride: a revised $Y$ scale of solvent ionizing power based on solvolyses of 1-adamantyl chloride," Journal of the American Chemical Society, vol. 104, no. 21, pp. 5741-5747, 1982.

[19] T. W. Bentley and G. Llewellyn, " $Y_{X}$ scales of solvent ionizing power," in Progress in Physical Organic Chemistry, vol. 17, pp. 121-158, John Wiley \& Sons, Hoboken, NJ, USA, 1990.

[20] D. N. Kevill and M. J. D'Souza, "Additional $Y_{C l}$ values and the correlation of the specific rates of solvolysis of tert-butyl chloride in terms of $N_{T}$ and $Y_{C l}$ scales," Journal Chemical Research (Synopses), vol. 5, pp. 174-175, 1993.

[21] T. W. Bentley, I. S. Koo, and S. J. Norman, "Distinguishing between solvation effects and mechanistic changes. Effects due to differences in solvation of aromatic rings and alkyl groups," Journal of Organic Chemistry, vol. 56, no. 4, pp. 1604-1609, 1991.

[22] T. W. Bentley, J.-P. Dau-Schmidt, G. Llewellyn, and H. Mayr, "Solvation effects adjacent to the reaction site. Differences in solvation between alkyl, alkenyl, or alkynyl and aryl groups in binary aqueous mixtures," The Journal of Organic Chemistry, vol. 57, no. 8, pp. 2387-2392, 1992.

[23] T. W. Bentley, G. Llewellyn, and Z. H. Ryu, "Solvolytic reactions in fluorinated alcohols. Role of nucleophilic and other solvation effects," The Journal of Organic Chemistry, vol. 63, no. 14, pp. 4654-4659, 1998.

[24] T. W. Bentley and M. S. Garley, "Correlations and predictions of solvent effects on reactivity: some limitations of multiparameter equations and comparisons with similarity models based on one solvent parameter," Journal of Physical Organic Chemistry, vol. 19, no. 6, pp. 341-349, 2006.

[25] T. W. Bentley, "Additivity rules using similarity models for chemical reactivity: calculation and interpretation of electrofugality and nucleofugality," Chemistry - A European Journal, vol. 12, no. 25, pp. 6514-6520, 2006.

[26] D. N. Kevill, N. HJ Ismail, and M. J. D'Souza, "Solvolysis of the ( $p$-methoxybenzyl)dimethylsulfonium ion. Development and use of a scale to correct for dispersion in Grunwald-Winstein plots," The Journal of Organic Chemistry, vol. 59, no. 21, pp. 6303-6312, 1994.

[27] D. N. Kevill, S. W. Anderson, and N. HJ Ismail, "Correlation of the rates of solvolysis of the benzhydryldimethylsulfonium ion. Application of the aromatic ring parameter," The Journal of Organic Chemistry, vol. 61, no. 21, pp. 7256-7262, 1996.

[28] D. N. Kevill and M. J. D'Souza, "Application of the aromatic ring parameter (I) to solvolyses of $\beta$-arylalkyl toluene- $p$-sulfonates," Journal of the Chemical Society. Perkin Transactions 2, no. 2, pp. 257-264, 1997.

[29] D. N. Kevill, M. J. D'Souza, and H. Ren, "Correlation of the rates of solvolysis of arylmethyl $p$ - toluenesulfonates: application of the aromatic ring parameter and a discussion of similarity models," Canadian Journal of Chemistry, vol. 76, no. 6, pp. 751$757,1998$. 
[30] D. N. Kevill and M. J. D'Souza, "Application of the aromatic ring parameter $(I)$ to solvolyses of extremely crowded alkyl derivatives," Tetrahedron Letters, vol. 39, no. 23, pp. 3973-3976, 1998.

[31] D. N. Kevill and M. J. D'Souza, "Sixty years of the GrunwaldWinstein equation: development and recent applications," Journal of Chemical Research, vol. 2008, no. 2, pp. 61-66, 2008.

[32] D. N. Kevill and M. J. D'Souza, "Use of the simple and extended Grunwald-Winstein equations in the correlation of the rates of solvolysis of highly hindered tertiary alkyl derivatives," Current Organic Chemistry, vol. 14, no. 10, pp. 1037-1049, 2010.

[33] M. J. D’Souza and D. N. Kevill, “Application of the GrunwaldWinstein equations to studies of solvolytic reactions of chloroformate and fluoroformate esters," Recent Research Developments in Organic Chemistry, vol. 13, pp. 1-38, 2013.

[34] M. J. D'Souza and D. N. Kevill, "Influence of sulfur for oxygen substitution in the solvolytic reactions of chloroformate esters and related compounds," International Journal of Molecular Sciences, vol. 15, no. 10, pp. 18310-18332, 2014.

[35] D. N. Kevill and M. J. D'Souza, "Correlation of the rates of solvolysis of n-octyl fluoroformate and a comparison with noctyl chloroformate solvolysis," Journal of the Chemical Society, Perkin Transactions 2, no. 2, pp. 240-243, 2002.

[36] M. J. D’Souza, M. J. McAneny, D. N. Kevill, J. B. Kyong, and S. H. Choi, "Kinetic evaluation of the solvolysis of isobutyl chloroand chlorothioformate esters," Beilstein Journal of Organic Chemistry, vol. 7, no. 1, pp. 543-552, 2011.

[37] J. B. Kyong, B.-C. Park, C.-B. Kim, and D. N. Kevill, "Rate and product studies with benzyl and $p$-nitrobenzyl chloroformates under solvolytic conditions," Journal of Organic Chemistry, vol. 65, no. 23, pp. 8051-8058, 2000.

[38] K.-H. Park, J. B. Kyong, and D. N. Kevill, "Nucleophilic substitution reactions of p-nitrobenzyl chloroformate," Bulletin of the Korean Chemical Society, vol. 21, no. 12, pp. 1267-1270, 2000.

[39] R. W. Taft Jr., S. Ehrenson, I. C. Lewis, and R. E. Glick, "Evaluation of resonance effects on reactivity by application of the linear inductive energy relationship. 1,2 VI. Concerning the effects of polarization and conjugation on the mesomeric order," Journal of the American Chemical Society, vol. 81, no. 20, pp. 5352-5361, 1959.

[40] H. J. Koh and S. J. Kang, "A kinetic study on solvolysis of 9fluorenylmethyl chloroformate," Bulletin of the Korean Chemical Society, vol. 32, no. 10, pp. 3799-3801, 2011.

[41] Microsoft Office, Excel 2010, Microsoft Corporation, Redmond, Wash, USA, 2010.

[42] KnowItAll Informatics System, “ADME/Tox 2008," Bio-Rad Laboratories, Philadelphia, Pa, USA, 2008.

[43] M. J. D’Souza, P. Dwyer, B. E. Allison, J. M. Miller, and J. Drohan, "Wesley College ignites potential with undergraduate student research program," CUR Quarterly, vol. 32, no. 2, pp. 41-45, 2011.

[44] M. J. D'Souza and Q. Wang, "Inter-institutional partnerships propel a successful undergraduate research program in chemistry," Journal College Teaching and Learning, vol. 9, no. 4, pp. 245-252, 2012. 

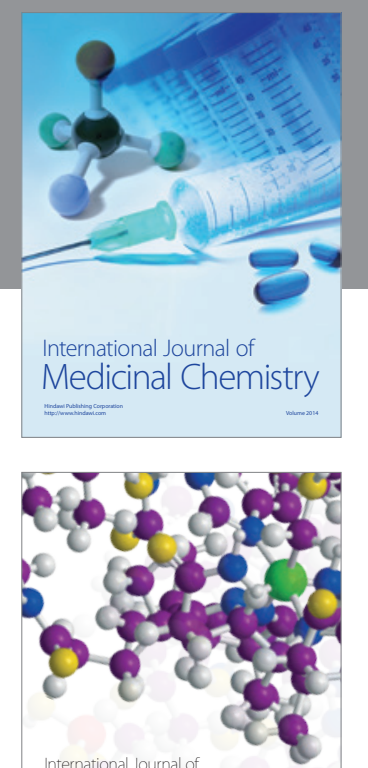

\section{Carbohydrate} Chemistry

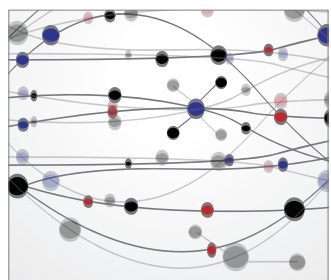

The Scientific World Journal
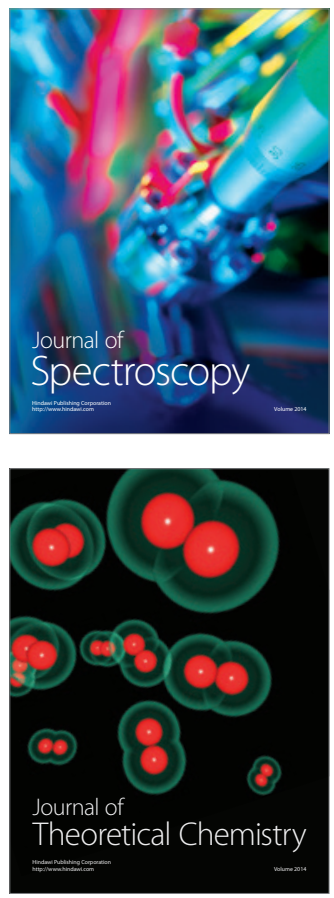
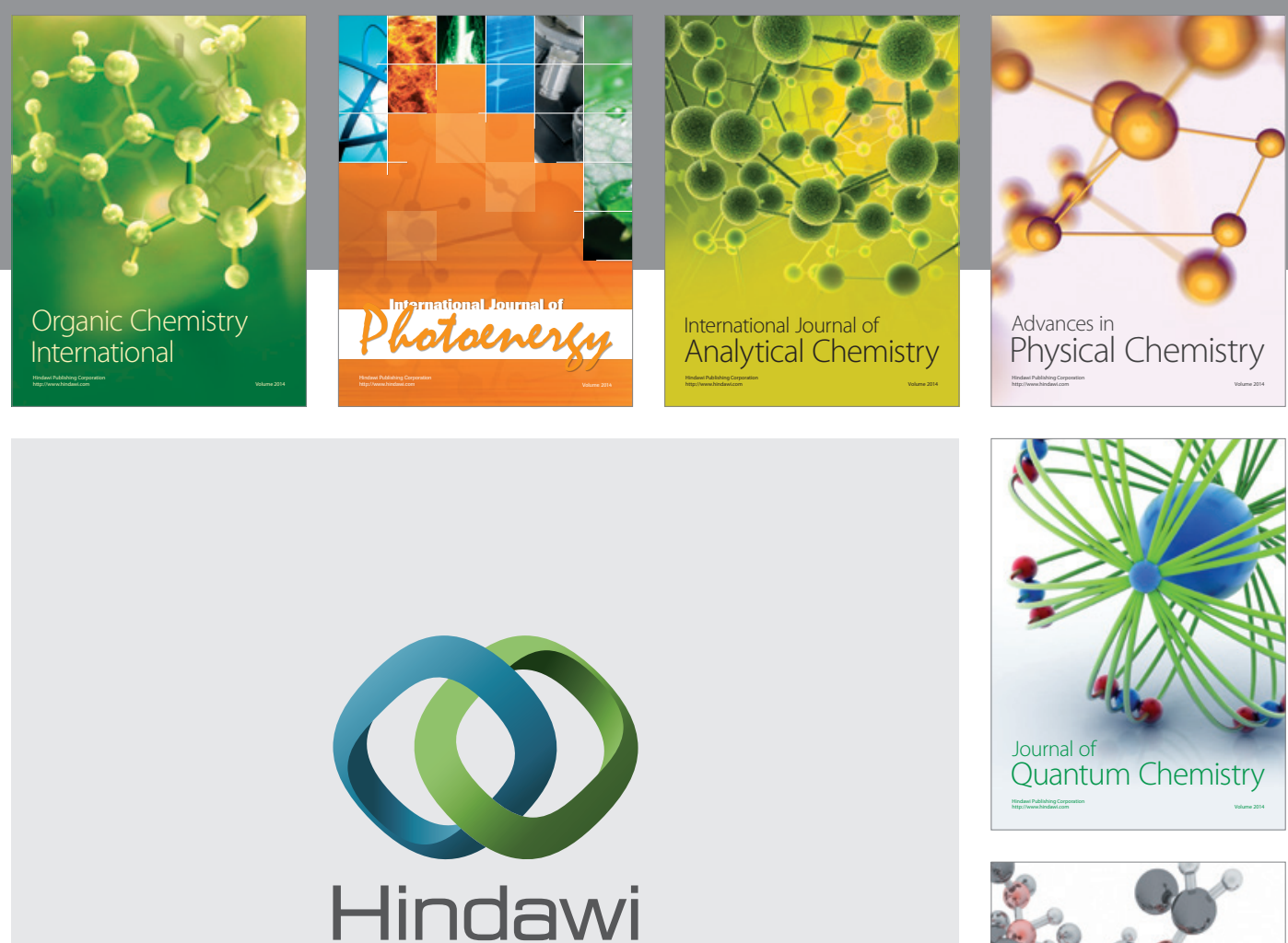

Submit your manuscripts at

http://www.hindawi.com

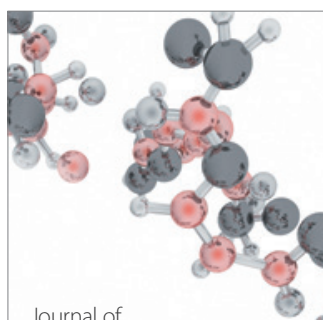

Analytical Methods

in Chemistry

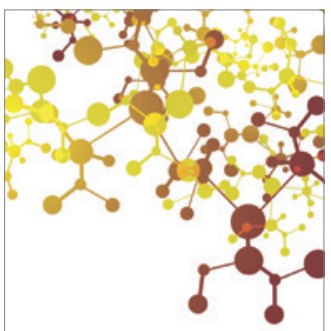

Journal of

Applied Chemistry

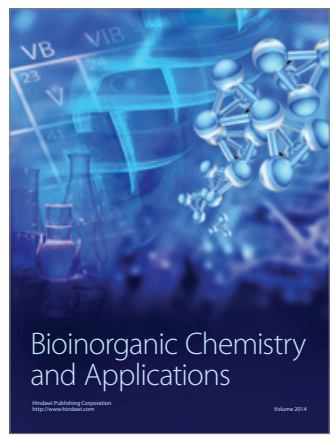

Inorganic Chemistry
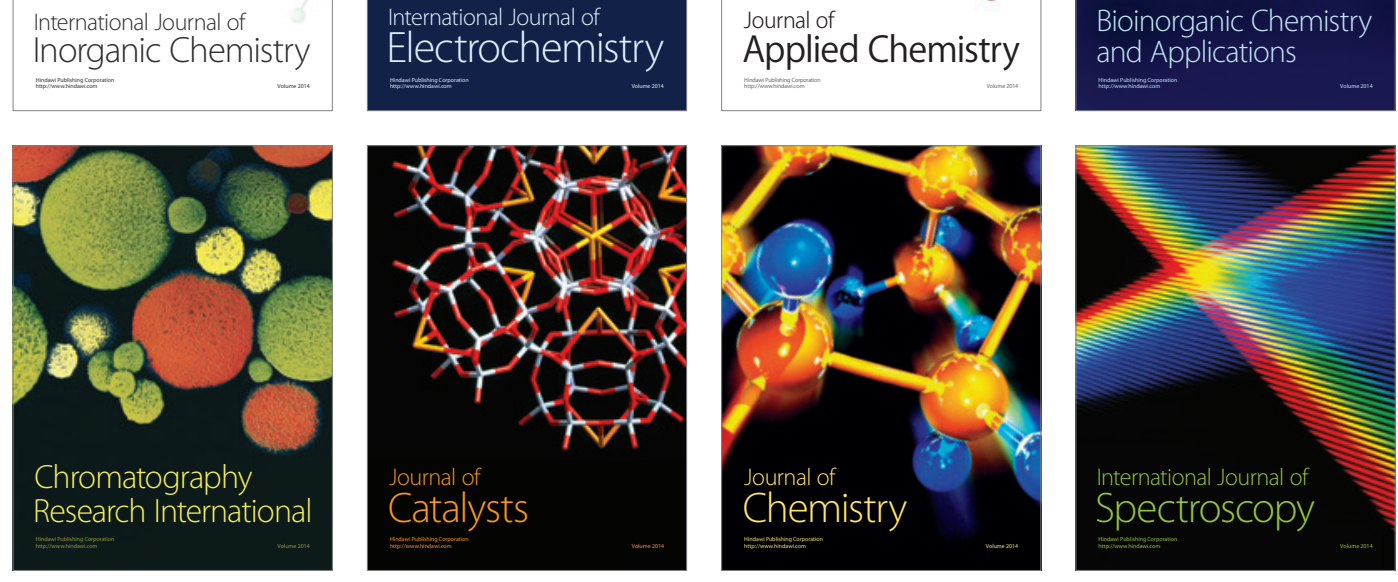